Research and Practice in Technology Enhanced Learning

Vol. 1, No. 1 (2006) 3-29

(C) World Scientific Publishing Company \&

Asia-Pacific Society for Computers in Education

\title{
ONE-TO-ONE TECHNOLOGY-ENHANCED LEARNING: AN OPPORTUNITY FOR GLOBAL RESEARCH COLLABORATION
}

\author{
TAK-WAI CHAN \\ Research Center for Science and Technology for Learning \\ National Central University \\ 300 Jhongda Road, Jhongli City, 32001 Taiwan \\ chan@cl.ncu.edu.tw \\ JEREMY ROSCHELLE \\ Center for Technology in Learning, SRI International
}

333 Ravenswood Ave, BN-376, Menlo Park, California, 94025, USA

jeremy.roschelle@sri.com

\section{SHERRY HSI}

Center for Learning and Teaching, The Exploratorium 3601 Lyon Street, San Francisco, California, 94123, USA sherryh@exploratorium.edu

\section{KINSHUK}

Advanced Learning Technologies Research Centre, Massey University Private Bag 11-222, Palmerston North, New Zealand kinshuk@ieee.org

\section{MIKE SHARPLES}

Learning Sciences Research Institute, Nottingham University Jubilee Campus, Wollaton Road, Nottingham, NG8 1BB, UK mike.sharples@nottingham.ac.uk

\section{TOM BROWN}

University of Pretoria, Telematic Learning 8 Education Innovation Lynnwood Road, Hillcrest, Pretoria, South Africa, 0002, South Africa tom.brown@up.ac.za

\section{CHARLES PATTON}

Center for Technology in Learning, SRI International

333 Ravenswood Ave, BN-376, Menlo Park, California, 94025, USA charles.patton@sri.com 


\section{JOHN CHERNIAVSKY}

National Science Foundation 4201 Wilson Boulevard, Arlington, Virginia 22230, USA jchernia@nsf.gov

\section{ROY PEA}

Stanford Center for Innovations in Learning, Stanford University Wallenberg Hall, Building 160, 450 Serra Mall, Stanford, CA 94305-205, USA

\section{CATHIE NORRIS}

Department of Cognition and Technology, University of North Texas Matthews Hall, 316-D, PO Box 311337, Denton, TX 76203-1337, USA norrise@unt.edu

\section{ELLIOT SOLOWAY}

Department of Electrical Engineering and Computer Science University of Michigan Ann Arbor, MI 48109, USA soloway@umich.edu

\section{NICOLAS BALACHEFF}

Laboratoire Leibniz 46 Avenue Félix Viallet, 38031 Grenoble Cedex, France Nicolas.Balacheff@imag.fr

\section{MARLENE SCARDAMALIA}

Institute for Knowledge Innovation and Technology OISE/University of Toronto 252 Bloor Street West, Toronto, Ontario M5S 1V6, Canada marlene@kf.oise.utoronto.ca

\section{PIERRE DILLENBOURG}

Swiss Federal Institute of Technology Ecole Polytechnique Fédérale de Lausanne 1015 Lausanne, Switzerland pierre.dillenbourg@epfl.ch

\section{CHEE-KIT LOOI}

Learning Sciences Lab, National Institute of Education Nanyang Technological University 1 Nanyang Walk, Singapore 637616 cklooi@nie.edu.sg

\section{MARCELO MILRAD}

Center for Learning and Knowledge Technologies, Växjö University MSI, Växjö University, Vejdes plats 6 och 7, 35195 Växjö, Sweden marcelo.milrad@msi.vxu.se 


\title{
ULRICH HOPPE
}

\author{
Institute for Computer Science and Interactive Systems, University Duisburg-Essen \\ Building LF, Lotharstr. 63/65, 47048 Duisburg, Germany \\ hoppe@informatik.uni-duisburg.de
}

G1:1MEMBERS ${ }^{\dagger}$

\begin{abstract}
Over the next 10 years, we anticipate that personal, portable, wirelessly-networked technologies will become ubiquitous in the lives of learners - indeed, in many countries, this is already a reality. We see that ready-to-hand access creates the potential for a new phase in the evolution of technology-enhanced learning (TEL), characterized by "seamless learning spaces" and marked by continuity of the learning experience across different scenarios (or environments), and emerging from the availability of one device or more per student ("one-to-one"). One-to-one TEL has the potential to "cross the chasm" from early adopters conducting isolated design studies to adoption-based research and widespread implementation, with the help of research and evaluation that gives attention to the digital divide and other potentially negative consequences of pervasive computing. We describe technology-enhanced learning and the affordances of one-to-one computing and outline a research agenda, including the risks and challenges of reaching scale. We reflect upon how this compares with prior patterns of technology innovation and diffusion. We also introduce a community, called "G1:1," that brings together leaders of major research laboratories and one-to-one TEL projects. We share a vision of global research, inviting other research groups to collaborate in ongoing activities.
\end{abstract}

Keywords: Technology-enhanced learning; research collaboration; pervasive computing; wireless technologies.

\section{Introduction}

Over the next 10 years, we anticipate that personal, portable, wirelessly-networked technologies will become ubiquitous and pervasive in the lives of learners - indeed, in many countries, devices like mobile phones or graphing calculators already have a high adoption rate among school-aged children. The eventual form of personal computing that will become most available to students is controversial. Today, one can find educators advocating everything from mobile phones and notebook computers to Tablet PCs and personal digital assistants (PDAs). In addition to these general-purpose computing devices, many researchers advocate specialized designed-for-learning devices. For example, graphing calculators are commonly used in high schools in North America and many European countries. Electronic English dictionaries are commonly used throughout Asia (upgraded with wireless communication capability). Alternatively, students can use portable gaming devices for learning (e.g. Nintendo ${ }^{\mathrm{TM}}$ Game Boy), corresponding with increased interest in the relationships between gaming and learning (Gee, 2003; Steinkuehler, 2004). In the

\footnotetext{
${ }^{\dagger}$ In alphabetical order: Rory McGreal, Athabasca University, Canada; Riichiro Mizoguchi, Osaka University, Japan; Miguel Nussbaum, Pontificia Universidad Católica de Chile, Chile; Hiroaki Ogata, University of Tokushima, Japan; Herman van der Merwe, Tshwane University of Technology, South Africa.
} 
near future, we can expect to see new types of devices emerging as well. The prices of these computing devices and network access will drop, according to Moore's Law and its corollaries (Moore, 1965).

This rapid advancement of mobile, connected, personal technology is already transforming the lives of students outside of school (Dede, 2005; Tapscott, 1998; Howe \& Strauss, 2000; Kasesniemi \& Rautiainen, 2002; Oblinger, 2003; Rheingold, 2002). As these devices become affordable for the majority of parents of schoolage children and for college students, mobile, connected, and personal devices will increasingly come to the attention of educational institutions. For example, the Massachusetts Institute of Technology (MIT) has proposed that $\$ 100$ laptop computers be purchased for school-aged children by states (MIT, 2005). At the same time, wireless services and Internet access in many countries will become available in most schools and universities and in public areas, from coffee shops to libraries. For example, Google has offered to bring free wireless access to the entire city of San Francisco (Peterson, 2005). With increasing availability, it seems inevitable that students will use personal devices for learning outside of school. This raises, for the first time, a new pressure and trend in adopting learning devices in schools: will students who come to expect mobile, connected, personal devices outside of school demand to use them within school? How will classroom life and everyday life be connected?

We see ubiquitous access to mobile, connected, personal, handhelds creating the potential for a new phase in the evolution of technology-enhanced learning, marked by a continuity of the learning experience across different environments. We term this "seamless learning." Seamless learning implies that a student can learn whenever they are curious in a variety of scenarios and that they can switch from one scenario to another easily and quickly using the personal device as a mediator. These scenarios include learning individually, with another student, a small group, or a large online community, with possible involvement of teachers, mentors, parents, librarians, workplace professionals, and members of other supportive communities, face-to-face or at a distance in places such as classroom, campus, home, workplace, zoo, park, and outdoors. Seamless learning space refers to the collection of the various learning scenarios supported by one-to-one technology. Exploration and investigation in the seamless learning space provides a potential to extend formal learning time, usually limited to the classroom, into informal learning time, to embrace opportunities for out-of-school learning driven by the personal interests of students, which may involve interacting with an online learning community, visiting museums, participating in community projects, or other venues (Computer Research Associations, 2005).

In this inaugural issue of RPTEL, we explore how the research community can respond to the opportunity and challenges of seamless learning space. Through design experiments (Brown, 1992; Design-Based Research Collective, 2003), researchers can look for the possible innovations in a target domain and thus confer technology with significance and value. In our case, we focus upon 
innovations in learning. By organizing and sharing information across design experiments, a collaboration of researchers can more rapidly and systematically explore the design space (Hawkins, 1997). For example, by collaborating across the globe, TEL researchers could take advantage of different student device preferences, understand cultural differences, and better address issues of scale. We see this new international journal as an important venue for creating, sharing, evaluating, and scaling research-based innovations more effectively and rapidly.

In this paper, we define technology-enhanced learning (TEL) and the affordances that one-to-one computing suggests, describe the kinds of collaborative and social learning TEL promotes, and briefly outline a research agenda for TEL. Next, we reflect upon how TEL might move from design experiments to adoption-based research and widespread use, and share an example of closing the digital divide through rapid technology adoption in South Africa. We also identify potential problems and serious risks with networked, pervasive computers. In the last section, we share a vision of global research collaboration in the context of the Asia-Pacific rim and the G1:1 community, a social network of leaders of major research laboratories and projects active in one-to-one technology-enhanced learning, and describe ways other research groups can participate in taking action in the global research for one-to-one TEL.

\section{One-to-One Technology-Enhanced Learning: Towards Seamless Learning Space}

\subsection{Definitions}

Various names or synonyms have been embraced in research that utilize digital technology to support human learning, including computer-assisted instruction, educational technology, educational computing, information and communication technology in education, and more recently, e-learning, distributed learning, asynchronous learning, and networked learning. In this paper, we use the term technology-enhanced learning (TEL) when technology refers to digital technology.

The notion of one-to-one (a ratio of at least one computing device for each student) was coined by Elliot Soloway and Cathie Norris. In their keynotes addressed in IEEE International Workshop on Wireless and Mobile Technologies in Education (WMTE2002) and International Conference on Intelligent Tutoring Systems (ITS2004), they argued that today's "personal computer" is not personal to a student in a school: the student most often has to share with others in a computer lab. They further pointed out that when everyone was able to afford a pencil, it changed how one learned (Papert, 1980). Similarly, when everyone could own a book, instead of sharing with others, it again changed how people learned. A similar change can happen if everyone owns and regularly uses a personal computing device.

As used in this paper, one-to-one TEL means that a student uses at least one computing device for learning. In some cases, a student may use more than one computing device or use a computing device together with some equipment in which 
there are some embedded micro-processors. We should take note that, in tens of years, when every student may already own a computing device as an indispensable tool for learning, the term one-to-one may not have meaning. The role of personal technology may become so seamless as to become invisible (Weiser, 1991).

\subsection{Significant properties of one-to-one devices}

An emerging new digital technology usually defines the scope and constraints of the ways it supports learning (Chan, 2002a). As learning environments move from the desktop to more ubiquitous and increasingly powerful portable devices, we can explore new, powerful properties specific to one-to-one technology. Several researchers have enumerated a number of features that make handhelds interesting for education (Klopfer, Squire \& Jenkins, 2002). These include:

(1) Portability that takes the computer to different sites and allows movement within a site so that the bounds of the classroom are extended to the limits of wireless networks;

(2) Social interactivity supported by via mobile and wireless technologies that enables direct peer-to-peer communication, data exchange, and face-to-face interactions and collaboration;

(3) Customization to the individual's path of investigation;

(4) Context sensitivity that automatically logs and aggregates usage for designing collaborative filtering systems and predictive user interfaces;

(5) Connectivity that creates a true shared environment via a common network for data collection among distributed devices;

(6) Combining digital and physical worlds with sensors, smart rooms, and ambient environments that capture real-world information of users, devices, and locations (geographical information systems) and represent it in a format that is usable in the digital realm.

Currently, educational applications that are available on mobile devices can be categorized into three main types; the first two were identified by Pinkwart et al. (2003):

(1) An interface to a "main" desktop program to extend the use of a desktop application for specific scenarios: the mobile device, in the extreme case, simply serves as a front end, for example, for outdoor data input.

(2) A standalone application running on the mobile device, with or without connection to a central desktop application, allowing collaboration via direct communication between the devices.

(3) A mobile device as an interface to a shared virtual space that resides on a server where the mobile device serves as a portal, in contrast to pure peer-topeer computing in which personal "spaces" are connected to each other. 
"Mobility hierarchies" have also been defined to support collaborative learning ranging from simple application tools such as calendar, contact, schedule, and other personal organization applications to the most complex applications that support multiple objectives such as collaborative work, data collection, analysis, and so forth (Gay, Rieger \& Bennington, 2002).

Another relevant dimension ranges from general-purpose tools to subjectmatter-specific tools. Although students and teachers have found benefits in generalpurpose tools that come with devices (calendars, to-do lists, word processing, spreadsheets, browsers), realizing the deepest benefits will likely require tools that are specific to the subject matter that students are learning (Vahey \& Crawford, 2002). In mathematics, a strong research tradition supports the use of graphing calculators (Ellington, 2003) as well as PDA-based graphing applications for teaching mathematics more deeply (Staudt, 2002; Tatar et al., 2003). In science, use of probes to gather data from the physical environment has been popular for a long time (Mokros \& Tinker, 1987) and has migrated to the handheld environment (Tinker \& Krajcik, 2001). More recently, handhelds have been used in participatory simulations that enable students to enact experiments that mirror real-world phenomena ranging from traffic to genetics to the spread of disease (Collela, Klopfer \& Resnick, 2001; Wilensky \& Stroup, 2000). Importantly, many science learning scenarios have moved between outdoor and indoor spaces. For example, Graham (1997) described students who used handhelds to prepare for a visit to a garden, conduct observations and environmental measurements during the visit, analyze the collected data, and write a report. Chen et al. $(2002,2004)$ similarly described mobile bird-watching and butterfly-watching learning systems for supporting independent learning. Hsi (2003) described a "nomadic" system for enhancing the content of exhibits in a science museum. Finally, researchers have explored applications in language arts. Research that examined improving students' writing with handhelds indicated that students showed improvement both qualitatively and quantitatively (Greaves, 2000; Joyner, 2002; Tinker \& Vahey, 2002).

Drawing upon research across a range of recent handheld projects, Roschelle \& Pea (2002) suggest application-level affordances around which one-to-one TEL has begun to organize: (1) augmenting physical space, (2) leveraging topological space, (3) aggregating coherently across all students, (4) conducting the class, and (5) capturing learning activity date. To put it simply, the many affordances of oneto-one computing across different settings and learning environments suggest an opportunity for seamless learning space.

\subsection{Supporting active, productive, creative, and collaborative learning}

While the properties of the devices are important, we suggest avoiding the techno-centric view as implied by notions of e-learning (learning supported by digital electronic tools and media) and m-learning (e-learning using mobile devices 
and wireless transmission). Unfortunately, these terms are often associated with a simplistic understanding of facilitating learning by delivering instructional content. In this view, the student is just a special type of customer and the instructional content is another type of e-commerce product. This simplistic view ignores the fact that modern education and pedagogy, irrespective of different theories and school of thought, converge in their high valuation of active, productive, creative, and collaborative learning methods much beyond the absorption of codified knowledge. (Hoppe, Milrad \& Kinshuk, 2002).

An important research theme in one-to-one TEL research has been around the theme of cooperative or collaborative learning. Zurita and Nussbaum (2004) designed specific activities aligned with principles of cooperative learning and experimented with those activities in elementary school mathematics and language arts, finding impressive gains in students' outcomes. Tatar et al. (2003) describe a range of collaborative science and mathematics activities that have been tested in classrooms and make use of wireless connectivity. Stroup and colleagues (2002) focus on the affordances of wireless connectivity for group activities in the mathematics classroom. The wireless features of one-to-one TEL promote collaboration in groups of learners (Vahey \& Crawford, 2002; Staudt, 2002).

Consequently, seamless learning space consists of scenarios in which learners are active, productive, creative, and collaborative across different environments and settings.

\subsection{Applicability of social learning theories}

While the properties of one-to-one devices may suggest and constrain uses, they will not determine educational use. Human learning is an extremely complex phenomenon and device capabilities must be paired with appropriate learning theories. The concept of seamless learning space suggests that one-to-one TEL may seek its philosophical and conceptual roots in social learning utilizing what we know about such as discourse, communities of practice, collaborative learning, internalization of social processes, participation in joint activity as well as cognitive, cultural, and media literacy perspectives.

An example of an integrated social learning approach that utilizes highly accessible technology is "knowledge building" (Scardamalia 2002; Scardamalia \& Bereiter, 2003). Scardamalia and Bereiter argue that creative work with ideas is integral to knowledge work in a knowledge society, and that the fundamental task of education is to enculturate youth into a knowledge-creating culture where sustained idea improvement is the norm. Knowledge building extends beyond learning, resulting in the creation, modification, and advancement of ideas that live "in the world." Ideas that are made explicit are available to be worked on and used by other people, engaging students in the knowledge creation process from an early age to the most advanced levels of theorizing, invention, and design, and across the spectrum of organizations that generate knowledge. Ideally, all participants 
are legitimate contributors to the shared goals of the community, all ideas are treated as improvable, and all have a sense of ownership of knowledge advances achieved by the group. Through links across virtual communities and to the rich resources of the Internet, students join the worldwide community of knowledge builders. With one-to-one technology and broader attempts at fostering technological and new media literacies, these visions would have a better chance to be realized.

We see one-to-one TEL as providing an opportunity to realize a vision of social learning spaces that is informed by social learning theories such as knowledge building.

\subsection{Amalgamating scenarios across TEL subfields}

While social learning theories may form a theoretical foundation for seamless learning space, they may evolve and are extended when researchers explore different learning scenarios in the TEL space. This is because these scenarios are largely generated by amalgamating existing TEL subfields. Why? It is natural for designers of one-to-one learning scenarios to ask questions such as: How should individual and social learning be orchestrated? How do individual intelligent tutoring techniques and computer-supported collaborative learning methodologies complement each other in these scenarios? For example, if a social learning researcher who designs social learning scenarios in a one-to-one classroom cares about continuity of experience, the researcher has to include home learning with the same device also. As a natural part of home learning, individual learning must be included in the design repertoire of the researcher. By the same token, an intelligent tutoring researcher may find it does not make much sense if all students in a one-to-one classroom quietly work with their own intelligent tutoring systems. It would be more productive if individual intelligent tutoring in the classroom is coordinated wirelessly by the teacher and gradually includes small group learning.

Moreover, one-to-one TEL researchers may extend their horizon to emerging subfields such as digital game-based learning (Gee, 2003), using wirelessly connected digital learning toys; ubiquitous learning (Pea et al., 2003), where one can interact simultaneously and unobtrusively with abundant physical objects, including digital wearables, embedded with multiple micro-sensors reacting to external stimuli; and biological learning (Byrnes, 2001; D’Mello, 2005; Chan et al., in press), in which new designs for learning environments may be informed by new findings about human attention, memory, and emotion. When Chan and his colleagues (1992) enumerated the number of learning scenarios in which student dyads learned with personal computers connected in pairs, they found as many as 768 learning scenarios. It is expected in addition to the new affordances of 1:1 technology, there will be numerous learning scenarios generated by amalgamating existing and emerging TEL subfields, a salient feature of seamless learning space. 


\section{A Research Agenda for TEL}

The many technology-enhanced learning scenarios and affordances of one-to-one computing raise many key social, pedagogical, and technical research questions, some of which include the following:

(1) How should we best leverage the potential value of ubiquitous, emergent, and multiple social interactions for learning? Are "smart mobs" also "learning mobs", and in what ways?

(2) How can learning productively leverage both the virtual world and the physical world at the same time, especially when absorption in one medium interferes with metacognitive awareness or when attention switching might contribute to cognitive overload?

(3) Rather than simply carry devices across locations, how do we create new designed-for-learning environments by redesigning physical sites such as historical places, community centers, and other public spaces to support new "ecologies for learning" (see Barron, 2004; Sharples, 2003)?

(4) What are the new digital-divide and equity issues when one-to-one computing is realized and device ownership is no longer an issue?

(5) How might instructional supports and devices be designed to switch between scenarios or settings with different configurations?

(6) How do we achieve a technical level of semantic interoperability to allow intelligent learning software components to be easily exchanged and re-used? (see Koedinger, Suthers \& Forbus, 1999; Roschelle et al., 1999)

(7) How do we learn from and reconcile the rich networked learning that children and young adults are engaging in as technology-fluent, powerful multimedia communicators outside of school, when they are forbidden to use them for school?

(8) How do we design TEL to minimize risk and protect privacy as personal data, school performance, and other social information become more globally available?

These and other research questions will need to be addressed as one-to-one TEL gains wider adoption in the Asia-Pacific rim and across the world.

Across different countries and regions in the Asia-Pacific, it is now widely accepted that education in the 21st century needs to prepare citizens for 21st century skills, competencies, and dispositions instead of those of the 19th or 20th century. Current educational reforms in many countries stress the importance of deep learning that fosters conceptual understanding and transfer, lifelong learning skills, and the ability to learn or unlearn. Policymakers in these countries and regions know they need to advance or reform their educational systems but they do not know how, or they are not prepared to take risks in tinkering with educational systems that have in many ways worked in the past. Major questions exist as how to foster deep and meaningful learning. These issues are especially 
important in many Asian countries with their more centralized education systems (as compared with the West) and the strong traditional emphasis on standardized examinations.

In this next section, we explore the key question of moving from design studies to widespread adoption-based research.

\section{Crossing the Chasm to Adoption-Based Research?}

It is hard to predict the future. Some say, "The best way to predict the future is to invent it." (Kay, 1971). Others note, "As I've said many times, the future is already here, it's just not very evenly distributed" (Gibson, 1999). In this section, we review the challenges of reaching scale, as well as the significant risks and uncertainties. Despite many causes for general optimism, educational reforms do not always stick. An example is that more than forty years ago, due to the superior advancement of space technology by the Soviet Union, the United States funded various mathematics reform curricula commonly known as New Math. Now, these curricula have largely disappeared (see http://www.csun.edu/ vcmth00m/AHistory.html). Critics of educational technology charge it is "oversold and underused" (Cuban, 2003).

Fortunately, there is research on technological innovation and diffusion processes that may help us develop a sense about the pace of changes in education in the forthcoming years (Rogers, 1995). This research suggests our time frame of thinking, anticipating, and planning should be in terms of decades. Technological advancement is faster than its adoption. Technology adoption is gradual, going through several phases. According to Rogers, the first group, the "innovators," are interested in and often adopt innovations for the sake of innovation itself. They can help themselves without clear directions, expectations, or guidance. The next group, the "early adopters," consisted of technology enthusiasts or those who see the potential for large return on their investment. The "early majority" are more pragmatic users. They are not pioneers and do not easily take risks. They look for incremental and measurable improvement and seek opinions of other users with experience. The "late majority" are those who are against innovations. They wait until the technology has become mature and the price has gone down and then they will comply with the new paradigm. The "laggards" will not adopt the innovation at all and often list the discrepancies between the original innovation promises and existing practices.

To better grasp a sense of what may be happening in one-to-one TEL, it is useful to have a rough timeline. For this reason, let us postulate that it will take a century to settle with the change in education brought about by technology. A sensible beginning point of time was around 1995 when the Internet rapidly expanded to almost every social sector. This means that in the forthcoming 40 years, there will be an upsurge of rapid changes in education until 2045; the pace of change will then slow down afterwards as shown in Fig. 1. 


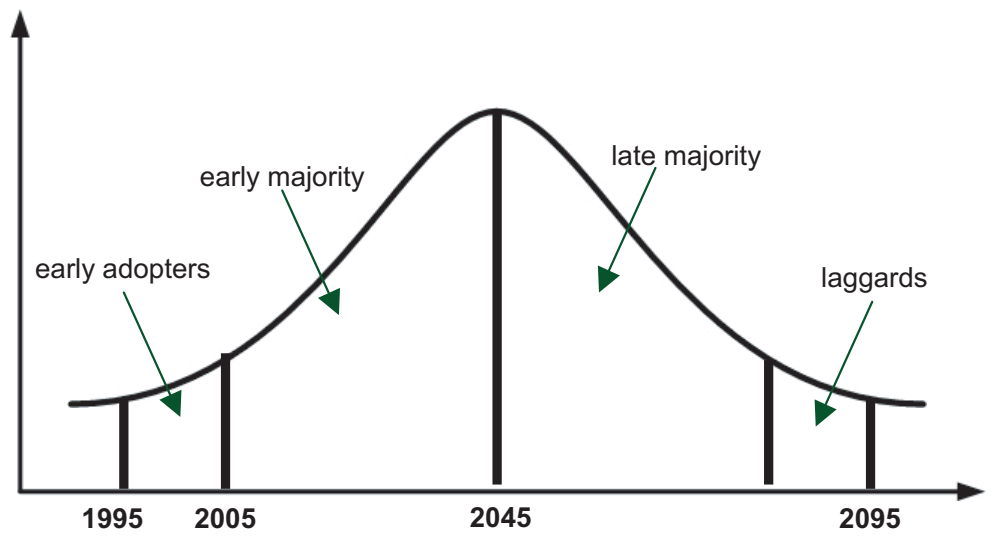

Fig. 1. Groups of adopters.

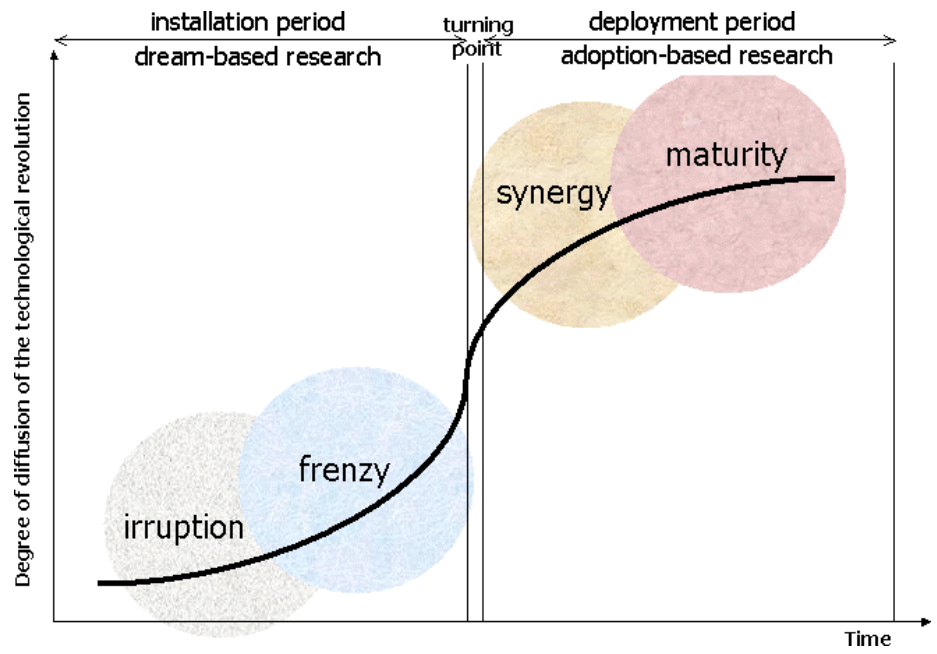

Fig. 2. Four phases of technological revolution.

TEL researchers who have worked with teachers for years in their experiments in schools in the past have noticed a similar phenomenon in the subset of enthusiastic teachers who are willing to adopt technology in their teaching practices. This is exactly what Moore (1991) put forward: there is a gap between the early adopters and early majority, as shown in Fig. 1. It is so hard to get across this gap that Moore called the gap a "chasm." Chan (2002a) has argued that, from the technological perspective, the wireless and mobile technologies may bring about the integration of all developed digital technologies in the past. With this integration, the corresponding emerging subfield of TEL, mobile learning, may take a leading role in crossing the chasm. Of course, there are more questions related to this chasm crossing to be 
asked. What will enable technology to cross the chasm in education? Under what conditions are pragmatic teachers willing to allow technology to be used in their daily teaching practices? And under what policies and conditions will education institutions change to accommodate the new technology fluencies demonstrated by learners outside the classroom? Our interest in seamless learning space suggests this question: Could use of one-to-one TEL outside of the classroom become a driver within the classroom?

Perez provides another avenue of viewing Moore's notion of chasm, which lends additional precision to our question. Perez was inspired by the work on business cycles by the economist Schumpeter (Perez, 2002). In 1939, Schumpeter pointed out that the major waves of economic growth and technological transformation are successive industrial revolutions. Perez identified five recurring waves of parallel phases in the past 230 years, beginning with the original "Industrial Revolution." All waves started with the emergence of a new technology or a radical innovation. For the digital technology revolution, it was the Intel microprocessor announced in Santa Clara, California, in 1971. The new technology was followed by a period of explosive growth of investment, leading to great turbulence and uncertainty in the economy and, finally, to disappointment after the bursting of the bubble. However, the upsurge of the new industry in that period took place in an environment still dominated by the old institutions. Perez called this the period "installation" period, which is further subdivided into two phases, "irruption" and "frenzy." The irruption phase inaugurates the surge that begins with the big bang of the technological innovation while the frenzy phase, the later phase of the installation period, allows financial capital to take over with immediate interests overruling the operation and paper economy decoupling the real economy. After the bursting of the bubble, it comes to a "turning point" for rethinking and rerouting development. After that is a period called "deployment," which is further subdivided into "synergy" and "maturity" phases. This is a period of relatively stable and prosperous development. Social institutes have been so accustomed to the new technology that the technology becomes common practice. Also, in this period, experiences of political and social changes have accumulated to such a stage that the need of a new regime of regulation becomes apparent. In the last two phases, the synergy phase and maturity phase, technology systems and products exist in a saturated market with other mature technologies, often described as the true golden age that prepares for the start of another technological revolution, as shown in Fig. 2.

Incorporating TEL development into Perez's framework, for each advent of digital technology innovation, we suggest thinking of the installation period as the romantic, exploratory, "dream-based" phase of TEL research (Chan et al., 2003; Roschelle \& Jackiw, 2000). We suggest thinking of the deployment period as "adoption-based" research. While most one-to-one TEL is in an early dreambased phase, at least one handheld technology has already entered "adoption-based research" - graphing calculators. National testing in the United States has found a high correlation between frequent use of graphing calculators and performance at 
the "proficient" and "advanced" levels of mathematics (NCES, 2001). A sufficient number of experimental studies of graphing calculators have been performed to do a meta-analysis and the meta-analysis reveals significant effects (Ellington, 2003). While some might protest that graphing calculators are not "true" one-to-one TEL technologies because they lack networking, we note that wireless networking capabilities recently have been added to Texas Instruments products. A similar case might be made that student response systems or "clickers" are a (simplistic) one-to-one TEL that has already entered the phase of adoption-based research (Abrahamson, 2000; Huang, Liang \& Wang, 2001; Roschelle, Penuel \& Abrahamson, 2004; Liang et al., 2005; Chen et al., 2005).

Another sign that one-to-one TEL is on the cusp of increased levels of adoption is the tension between rapid and gradual crossing views. The rapid crossing view is ready for massive deployment. Researchers of this view will persuade policymakers to invest in schools by purchasing a computer for each student. Examples of such effort are laptop projects in schools in England, such as Ninestiles and Cornwallis, the state of Maine in the United States, and the "electronic schoolbag" project in some provinces in France. Some of these projects give a laptop to all students in a particular grade. The "Notebook University" program in Germany supported 12 pilot universities to subsidize students buying notebooks and create best practice examples of using notebooks in different subject areas to enrich a variety of learning scenarios on campus.

Researchers that hold the gradual crossing view do not believe in revolution, but in evolution (Owston, 2003). They believe technology goes nowhere without a culture of use and concern about the values and beliefs of stakeholders such as teachers and the stability of the educational system. Researchers with this view will favor changes through slight adjustments (Chan, 2002b; Chan, 2003).

The fact that one-to-one TEL is already on both sides of Moore's chasm and Perez's framework suggests that we are at a critical period of one-to-one TEL research and development. Our designs have to satisfy not only users who are innovators or visionaries but also pragmatists. It is even better if we can address the criticism of skeptics. "Pedagogical applications are often led down the wrong road by complex views of technology and simplistic views of social practices.... Further research is needed that tells the story of rich pedagogical practice arising out of simple wireless and mobile technologies" (Roschelle, 2003).

We admit that as far as the current status of research and development of TEL is concerned, we are still far from being confident about convincing teachers that adopting one-to-one TEL can be effective for their teaching. It is still too complex and too distant from their immediate needs. It is useful to elaborate what is meant by effective here. Humans are intelligently economical, that is, they like to do the same work with less time and effort without sacrificing quality (Bourdieu, 1977; Pea, 1993). This means TEL has to be efficient in helping teachers accomplish their work. Not many TEL research projects have been looking at this issue yet. Some initial studies on one-to-one research such as those that appeared in two special issues of 
the Journal of Computer Assisted Learning show that formative evaluation can be done rather efficiently (Huang, Liang \& Wang, 2001).

\section{The Digital Divide Issue: The Case of Africa}

As one might expect, a vision of one-to-one technology-enhanced learning is not without barriers in providing individual ownership and access to a device for learning. One critical barrier is the "digital divide" (Emmott, 2003). There are currently two opposing views about the future of the digital divide amongst researchers. One view is that continuous developments in digital technology will bring about a widening of the digital divide as less and less of the developing world and poor communities will be able to catch up with new technologies. In this view, the percentages of "haves" versus "have-nots" will continue to increase. The other view is that new digital technology developments will make it possible to lower the cost of technology, so developing countries will leapfrog from little or no technological infrastructure to the latest appropriate wireless infrastructures, and that the number of available computational devices will increase to such an extent that it will be possible to narrow the digital divide.

The case of mobile phones in Africa provides one promising case of narrowing the digital divide. As an indicator of this, the Nua Internet Surveys (July 15, 2002) reported that, according to the National Information and Communication Technology Policy, the number of mobile phone subscribers in Uganda grew from 3,500 in 1996 to a total of 360,000 in 2002 (East African, 2002).

When Vodafone UK sent Michael Joseph to Kenya in July 2000 to set up Safaricom, a cell-phone service operator jointly owned by Telkom Kenya, he did not expect the subscriber base to grow beyond 50,000 connections (Wachira, 2003). Today, both Safaricom and rival KenCell Communications (partly owned by Vivendi) have nearly 1.3 million cell-phone subscribers. This set-up is deeply rooted in the traditional African communal mode of living, which many urban dwellers have not abandoned.

The adoption rate of mobile technologies in Africa's developing countries is among the highest rates globally and forecasts estimate almost 100 million mobile users in Africa by 2005 (Shapshak, 2002). Between 1997 and 2001, the number of mobile phone subscribers in Africa annually had a triple-digit growth rate. The number of mobile subscribers in Africa rose further and increased by over 1,000\% between 1998 and 2003 to reach 51.8 million (ITU, 2004). Although the latest figures and statistics are not that readily available at this point in time, we believe that it will be much higher than expected.

It is thus obvious that the adoption rate of mobile technologies is exceptional in Africa. Africa is leapfrogging from an unwired, nonexistent TEL infrastructure to a wireless TEL infrastructure. Similar developments are taking place in many developing regions other than Africa, such as in rural areas of China and countries in South America. 
Though mobile phones are just one example of a technology, one can foresee how the narrowing of the digital divide will contribute to global participation. Howard, former Chief Information Officer Advocate and Advisor to the Chief Executive Officer of Sun Microsystems adds the following about the narrowing of the digital divide:

In the decade ahead, cell phones and wireless will allow global participation on a scale not yet seen. New online communities will emerge and social networking will expand. Free access to information and a means for anyone to participate will be available to huge numbers of people previously excluded from the information age. This will have a significant impact in politics, government, business, religion and education on our institutions. (Howard, 2005)

We are not alone in our concerns for closing the digital divide. The Stellenbosch Declaration (Cornu, 2005) was produced by an expert group of educators and specialists of TEL from six continents, who met and worked together in Stellenbosch, South Africa, at the IFIP 8th World Conference on Computers in Education in 2005. They proposed a Digital Solidarity Action to fight against the digital divide. This action intends to "define as the most important aim for the next five years, that every child in the world has access to a digital information and communication infrastructure; support projects that establish collaboration of students and teachers on a global level and through networks; and express the will to share digital educational content among education systems of different countries while respecting international property rights."

\section{Potential Downsides}

Although we have highlighted the promise and opportunities wrought by the advent and diffusion of one-to-one TEL, there are also problematic issues that must be responsibly addressed. As will be evident, many of these issues are not at all unique to one-to-one TEL, but are correlated with uses of computing in its emerging forms and functions in other societal domains. Five issues are identified and briefly defined here:

(1) Blending informal and formal environments with pervasive computing as a threat to a balanced life. As the boundaries between formal and informal environments for education and learning become ever more permeable with one-to-one pervasive computing, we may experience an educational version of the negative effects that are emerging in the workplace when formal and informal work time is blurred. These include added stresses due to the invasion of externally controlled work activities into all of one's life-spheres. These reduced boundaries can have unfortunate side effects of expectations that one can be available for work or, in the case of TEL, for learning or educational demands anytime and anywhere. Imbalances in the lifespace can propagate from the lack of boundaries - so that people find it increasingly difficult to lead whole lives in which 
work, learning, family, community, spirituality, entertainment, exercise, and so on, are maintained in a healthy balance. Unfortunately, the optimistic prediction by Landauer (1988) of the world in 2020 as a place with much more leisure time and less stress - all enabled by ICT — now seems a misguided pipedream.

(2) Challenging data security, integrity, and privacy issues. In a series of four research workshops on a vision and research agenda for "cyberinfrastructure for learning and education in the future" sponsored by the National Science Foundation (Computing Research Association, 2005), this was a persistent theme. Workshop participants anticipated that the many promises and prospects of personalized learning environments will include a "lifelong learning chronicles" portfolio of learning relevant processes and outcomes. These could include recorded and indexed audio-video records, student work, multimedia reports, and the like. Yet the participants kept re-visiting the risks and challenges concerning data security, integrity and privacy issues that loom large as a learner's thinking, spatial location, peer interactions, and other technology-mediated aspects also become subject to surveillance. Misguided uses may proliferate if great care is not taken in designing such systems. For example, we asked: What are the risks as well as benefits of new technology-enabled assessments? What are the potential dangers of establishing and sharing persistent portfolios of students' learning and performance? What are the current constraints (policy, cultural, technological and legal) in introducing invasive automatic assessment into learning environments? What new policies and tools can mitigate the risks? If distributed learning environments for one-to-one TEL are designed to collect and manage large amounts of data about learners' activities, the onus is on the research community to productively solve problems of privacy, security, and ownership of potentially sensitive data. Who will have control of such data and with what warrants?

(3) Being co-opted into the industry logic of a persistent digital divide. In a National Research Council report (Pea et al., 2003) resulting from U.S. workshops convening learning scientists, K-12 educators and computing/communications and publishing industries, an industry logic emerged that often goes unnoticed. For each new generation of more powerful, faster, processors from Intel or other chip manufacturers, new processor-intensive, bandwidth-sucking applications need to be developed in order to create the demand for upgrading the computers used in society and its various sectors. Intensive graphically-rich multiplayer games, Web applications using much more video compression/communication that can benefit from new hyper-threading chip architecture, and so on, are heavily seeded through investments by semiconductor companies in applications companies to create the new demanding applications to ensure the perpetuation of new cycles of computer upgrade - and thus, as a side effect, the perpetuation of the digital divide. To the extent that the one-to-one TEL community is pulled into these same dynamics by heralding the new applications that are leading-edge uses of ICT for education and learning, we are essentially becoming partners in industry logic that will establish a persistent digital 
divide. More advanced computers will always cost more and be out of reach of the less economically advanced communities and developing countries.

(4) The high environmental and ecological costs of low-cost pervasive computing. Stories and pictures of ecological havoc wreaked by the hundreds of millions of discarded computers and cellular phones are increasingly common in the news. Very poor children living near wastelands and slums in China and India, for example, are shown in photos experiencing toxic fumes as they melt lead solder to take out the parts of these discarded symbols of industrial progress that have some recycling value in their impoverished economic environment. Again, while this issue is not specific to one-to-one TEL, in advocating the proliferation and use of computers and mobiles throughout the globe in far greater numbers than today, this ecological impact problem will only intensify. We need to take responsibility for promoting policies and awareness of this issue, and advancing an action agenda that makes choices of technologies in favor of companies that develop more environmentally and recycling friendly approaches to this critical concern.

(5) Learning supported by one-to-one TEL that is unethical and socially destructive. It goes too often without observation that the same remarkable power of wireless computing and anytime-anywhere accessibility of information that spurs the learning process and outcome promises also supports antisocial learning. Antisocial learning may occur in building terrorist networks, advancing drug and money-laundering operations, and so on. It is not evident what the best response of the one-to-one TEL community to these issues should be, but curriculum theory and educational practices need to be particularly attentive to promoting civic and moral education that will create citizens less prone to accept the new "fingertip-accessible" risks of entering into online worlds of crime, corruption, and illegal money-making activities.

\section{Towards Global Research Collaboration}

Our anticipation of large-scale technological innovations in education leads us to believe that the potential and challenges of one-to-one TEL deserve a coordinated global response. No nation can avoid the changes which literally will be carried into learning settings by the learners. International collaborations give TEL researchers exposure to many different educational settings and many different educational systems so that the robustness of TEL innovations can be tested across multiple environments. Research groups working in multiple educational systems bring unique perspectives to TEL. There is urgent need of putting together complementary strengths and contexts and combining our insights as rapidly as possible to make a greater impact and further elevate our research quality at the same time. Research generally has had a small voice in national educational outcomes; we can speak louder if we speak together. In the remainder of this paper, we report on one mechanism through which such a response may emerge. 


\subsection{Formation of $\mathrm{G1:1}$}

G1:1 (pronounced as "G one one") is a self-organizing global networked community that consists of leading research teams in one-to-one TEL (see www.g1to1.org). Because G1:1 is loosely structured, it allows the flexibility and inclusiveness for accepting emerging one-to-one prominent research groups across the globe and ease of creating various one-to-one related events or initiatives. The core G1:1 members have extensive connections, and the informal nature of G1:1 allows them to connect many formal organizations or structures (e.g. Kaleidoscope, ISLS, APSCE, IEEE, AIED Society, mLearn) through overlapping membership and shared events.

G1:1 has evolved over a series of events. The idea was initiated by Marcelo Mirada in the summer of 2002 at the same time as the first IEEE International Workshop on Wireless and Mobile Technologies in Education (WMTE2002) held in Växjö University, Sweden. Tak-Wai Chan then organized two workshops to explore the idea in 2003 and 2004 in Taiwan. In 2005, more workshops and panels were organized in Taiwan, South Africa, Japan, and Singapore that involved critical discussions, scenario planning, and ways to promote international academic and industry partnerships (see http://www.g1on1.org/about_us/history.php).

\subsection{Mission of $61: 1$}

The mission of G1:1 is still evolving. At present, there are three ways that G1:1 may make an impact in education:

(1) Stimulating active debate across the real and artificial boundaries of nations, professional societies, conference- and journal-based communities;

(2) Informing the one-to-one global movement (e.g. through comprehensive bibliographies);

(3) Fostering international research collaborations (e.g. through exchange of graduate students and research materials).

As the foremost mission, G1:1 believes that high-quality research should be the basis of every intention and action impacting one-to-one research and development. Because the G1:1 community is an open social network, research groups can participate by learning about future community events as well as registering a project or testbed in the G1:1 online inventory posted on the Website at http://www.g1on1.org/.

\subsection{G1:1 efforts}

As concrete examples of the diversity of prior events and on going efforts that G1:1 has organized, we highlight three strands of work that TEL research groups can potentially benefit from and make contributions to. 


\subsubsection{Scenario-based planning}

Through a series of workshops, G1:1 is developing scenarios that may be used by researchers and policymakers to formulate strategic plans that are more likely to succeed in a variety of future environments. The process of scenario-based planning was first formalized by SRI International in 1969, in work for the U.S. Department of Education and other agencies (Nielson, 2005.) Since the oil shocks of the 1970s, and the preparedness of Royal/Dutch Shell to weather those shocks based on scenariobased planning, academics and practitioners used scenario-based methods as key elements of strategic planning.

For example, in the Taiwan event (Roschelle et al., 2005) G1:1 researchers crafted plausible stories that highlighted the transformative potential of a "wikipedia"-style approach to the generation of educational content and an ISO-9000-style approach to capturing the creative and learning potential of games. In the Cape Town event, a rather different set of researchers concluded, in vivid contrast to the earlier session, that peer tutoring might not only be an interesting and effective method of education, but could plausibly become the dominant educational method for a large fraction of the world's students by 2015. Moreover, they faced head-on the issue of the digital divide - and what might plausibly arise to challenge its dominance. These researchers focused neither on cheaper technology, nor on hand-outs as the most plausible route out of the digital divide. Instead, they imagined the emergence of a new human right - the right to access to a broad social network — as the driving force that, while not guaranteeing every human the latest gadget, does bring focus to a most important aspect of technology.

Each of the narrative descriptions of alternate plausible futures poses both a challenge and an opportunity to TEL researchers worldwide. The challenge is to critically examine research programs in light of these future uncertainties and to "weatherproof" their strategy against multiple potential shifts in climate. The opportunity is to identify potential turning points and take action to "stack the deck" - even slightly — in the direction they foresee will have the most beneficial outcome for the world's students.

\subsubsection{Global network of testbeds}

G1:1 is working to define a global network of testbeds. A "testbed" here refers to a school, a college, an informal learning site such as a museum, or a company for on-job training, which has a strong institutional support and continuously collaborating with a one-to-one research team for a long period. A testbed is more than an experimental site of a particular research project. Through a long-term commitment, a testbed develops best practice and becomes a model for dissemination.

Integration of technology with teaching and learning culture is the key to success, but that takes time, possibly a long time (Krajcik, 2005) and requires extensive field study. A network of testbeds, in particular, a global network, will speed up the research. In the past, such a testbed has often been local to a nation. For example, 
there were pilot schools in the first phase of Singapore's Master Plan for information technology in schools. Similarly, Taiwan has some seed schools that serve the same function as a testbed. A G1:1 network of testbeds as the outcome of international collaborations among research teams will allow an institution, a school district, or a nation to "see the universal" from the local and specific.

\subsubsection{Component exchange community}

G1:1 is also working to define a mechanism of component exchange. Some exchange mechanisms are needed so that local and international researchers can share their nonproprietary research components for experimentation and data collection. For example, in order to collaborate, researchers need to identify small units of their research outcomes that would be useful for others. One institute can exchange components with another institute and thus can advance research work quickly with their own and others' components. Then they can proceed to study how users with different cultures adopt resulting outcomes. One obstacle is the protection of intellectual property, ideas, and other interests. Consequently, as part of the exchange mechanism, some legal procedures of protection should be in place.

Besides software, components can be some novel hardware, learning material, or even theories, ontologies, or protocols of learning activities (sometimes called scripts or activity models). An early example of such an international shared network in the LearnLab facility is at the Pittsburgh Science of Learning Center (http://www.learnlab.org/).

\section{Conclusion}

In this article, we have argued that three factors - (1) ubiquitous access to mobile, connected, and personal, handhelds, (2) the relentless pace of technological developments in one-to-one computing, and (3) the evolution of new innovative uses of these handhelds - will create the potential for a new phase in the evolution of technology-enhanced learning, characterized by "seamless learning spaces." By enabling learners to learn whenever they are curious and seamlessly switch between different contexts (such as between formal and informal contexts and between individual and social learning) and by extending the social spaces in which learners interact with each other, these developments, supported by theories of social learning and knowledge-building, will influence the nature, the process and the outcomes of learning. The space of social-cultural developments enabled by one-to-one TEL will unfold before us in the next decades. In particular, the ingenious or pervasive uses of these devices in some usage contexts may be close to the tipping points in terms of effecting fundamental shifts in the ways students learn in schools and outside of schools.

The G1:1 consortium, which was itself initiated by the Asia-Pacific research community, provides a key channel to design and study seamless learning experiences 
that consider both formal learning in the classroom and informal learning outside of the classroom. The demands and expectations of learners in the Asia-Pacific are high - consider the pervasiveness of mobile phones and handheld devices in countries and regions like China, Japan, Korea, Singapore, Taiwan, and Hong Kong; consider the learning demands of millions from countries like China for useful language, technical, and management skills; consider the capacity of manufacturers in the Asia-Pacific to competitively design and produce handheld devices with enhanced or new functionalities that are customized for local markets, including Asian language support. There is a strong imperative for exploiting the potential of one-to-one TEL for providing quality learning beyond high standardized test scores, and for supporting the diverse learning needs and demands of large populations of learners in the Asia-Pacific.

As a global research community, we can observe the future as it emerges before us or we can take action by seeking global collaboration to create a critical mass to take on the challenges of designing and evaluating innovations to support seamless learning space. By collaborating across the world, researchers could take a diversity of research approaches and goals, explore different types of handhelds and their uses in different contexts and settings, exchange good practices and research components, address important issues of engendering cultures of use and build up our capacity for one-to-one TEL research. For this purpose, G1:1 serves a global research community that shares, evaluates and explores the scaling of research-based innovations more effectively and rapidly through different research designs. By doing scenario-based planning for the future enabled by one-to-one computing, we plan to cope with uncertainties by envisioning multiple learning scenarios in future landscapes.

We anticipate that G1:1 can make a significant contribution to innovating and disseminating the educational uses of one-to-one TEL thus crossing the chasm to adoption-based research. We might create some of the conditions that allow the crossing of Moore's chasm in a shorter time, or reach Perez's turning point sooner than a natural evolutionary process would take us. To do so, we need to remain cognizant of the potential negative issues associated with one-to-one TEL discussed in the article, namely, the penetration of pervasive computing into all of one's lifespheres with potential for creating an unbalanced lifestyle; data security, integrity and privacy issues; persistent digital divide; high environmental and ecological costs of low-cost pervasive computing; and learning supported by one-to-one TEL for unethical and socially destructive purposes.

\section{Acknowledgments}

The authors would like to thank Yam San Chee for his patience and advice at the last stage of revising this manuscript and the constructive comments from Daniel Suthers for its further improvement. We especially thank the G1:1 discussion group for their inspiration and encouragement. This work was partially supported by the 
U.S. National Science Foundation under grant \# 0427783 and the National Science Council of Taiwan under grant \# NSC94-2524-S-008-003.

\section{References}

Abrahamson, L. A., Davidian, A., \& Lippai, A. (2000). Wireless calculator networks: Where they came from, why they work, and where they're going. Paper presented at the 13th Annual International Conference on Technology in Collegiate Mathematics, Atlanta, GA.

Barron, B. (2004). Learning ecologies for technological fluency: Gender and experience differences. Journal Educational Computing Research, 31(1), 1-36.

Bourdieu, P. (1977). Outline of a theory of practice, Cambridge University Press.

Brown, A. L. (1992). Design experiments: Theoretical and methodological challenges in creating complex interventions in classroom settings. Journal of the Learning Sciences., 2(2), 141-178.

Byrnes, J. P. (2001). Minds, brains, and learning: Understanding the psychology and educational relevance of neuroscientific research, New York: The Guilford Press.

Chan, T. W. (2002a). Keynote: Mobile learning: The 'last driver' to cross the chasm, International Conference on Computers in Education, New Zealand.

Chan, T. W. (2002b). Humanism in educational computing and digital technology. In T. W. Chan \& Y. P. Lin (Eds.), Initiating learning revolution - the first educational network city, EduCities, in the world (Chinese) (pp. 59-76). Yuan-Liou Publishing.

Chan, T. W. (2003). Slight adjustment: A strategy of disseminating technological innovations in K12. In T. W. Chan \& L. W. Huang (Eds.), Towards digital learning society (Chinese) (pp. 256-274). Yuan-Liou Publishing.

Chan, T. W., Chung, Y. L., Ho, R. G., Hou, W. J., \& Lin, G. L. (1992). Distributed learning companion systems - WEST revisited. In C. Frasson, G. Gauthier \& G. McCalla (Eds.) The 2nd International Conference of Intelligent Tutoring Systems, Lecture Notes in Computer Science (Vol. 608, pp. 643-650) Springer-Verlag.

Chan, T. W., Huang, S. T., Hue, C. W., Ko, H. W., \& Sheu, J. P. (2003). Presentation for the final review of the promoting university academic excellence project: Learning technology: Active social learning and its applications - from Taiwan to the world, National Central University, Taiwan.

Chan, T. W., Ko, H. W., Tzeng, O., \& Chou, C. Y. (in press). Optimal capacity building: Integrating brain-based learning and educational research into technology supported learning, Educational Technology Magazine.

Chen, Y. F., Liu, C. C., Yu, M. H., Chang, S. B., Lu, Y. C., \& Chan, T. W. (2005, November). A study on elementary science classroom learning with wireless response devices - implementing active and experiential learning. In Proceedings of the 3rd IEEE international workshop on wireless and mobile technologies in education (WMTE 2005) (pp. 96-103). Nov. 28-30, 2005, Tokushima, Japan.

Chen, Y. S., Kao, T. C., Yu, G. J., \& Sheu, J. P. (2002, August). A mobile scaffolding-aidbased bird-watching learning system, In Proceedings of the 1st IEEE international workshop on wireless and mobile technologies in education. August 29-30, Växjö University, Sweden.

Chen, Y. S., Kao, T. C., Yu, G. J., \& Sheu, J. P. (2004, March). A mobile butterfly-watching learning system for supporting independent learning. In Proceedings of the 2nd IEEE international workshop on wireless and mobile technologies in education. March 23-25, JungLi, Taiwan.

Cuban, L. (2003). Oversold and underused: Computers in the classroom. Cambridge, MA: Harvard University Press. 
Computing Research Association (2005, November). Cyberinfrastructure for education and learning for the future: A vision and research agenda. (Co-authored by, in alphabetical order, Sharon Ainsworth, Margaret Honey, W. Lewis Johnson, Kenneth Koedinger, Brandon Muramatsu, Roy Pea, Mimi Recker, and Stephen Weimar). Washington, DC: Computing Research Association.

Colella, V., Klopfer, E., \& Resnick, M. (2001). Adventures in modeling: Exploring complex, dynamic systems with StarLogo. Teachers College Press.

Cornu, B. (2005). Stellenbosch declaration, ICT in education: Make it work. In International federation for information processing (IFIP TC3). (www.terryfreedman.org.uk/artman/uploads/thestellenboschdeclaration.pdf)

Dede, C. (2005). Planning for neomillennial learning styles. Educause Quarterly. 28(1). (also available at: http://www.educause.edu/pub/eq/eqm05/eqm0511.asp)

Design-Based Research Collective. (2003). Design-based research: An emerging paradigm for educational inquiry. Educational Researcher, 32(1), 5-8.

D’Mello, S. K., Craig, S. D., Gholson, B., Franklin, S., Picard, R., \& Graesser A. C. (2005). Integrating affect sensors in an intelligent tutoring system. In Affective interactions: The computer in the affective loop workshop at 2005 International Conference on intelligent user interfaces (pp. 7-13). New York: AMC Press.

East African, July 8 (2002). Ugandan internet and mobile use soars. Newspaper article cited in TAD Consortium August 2002 Information Update No. 2, Telematics for African Development Consortium, SAIDE, Johannesburg, South Africa.

Ellington, A. (2003). A meta-analysis of the effects of calculators on students' achievement and attitude levels in pre-college mathematics classes. Journal for Research in Mathematics Education, 34(5), 433-463.

Emmott, B. (2003). 20:21 Vision - the lessons of the 20th century for the 21st. The Penguin Press.

Gay, R., Rieger, R., \& Bennington, T. (2002). Using mobile computing to enhance field study. In T. Koschman, R. Hall \& N. Miyake (Eds.), CSCL 2: Carrying Forward the Conversation (pp. 507-528). Mahwah, NJ: Lawrence Elbaum.

Gee, J. (2003). What video games have to teach us about learning and literacy. Palgrave MacMillan.

Gibson, W. (1999). The science in science fiction. On a National Public Radio broadcast of "Talk of the Nation" with interviewer Terri Gross on November 30, 1999. (http://www.npr.org/templates/story/story.php?storyId=1067220)

Graham, B. (1997). The world in your pocket — using pocket book computers for IT. School Science Review, 79(287), 45-48. Retrieved October 20, 2005. (http://www. bgfl.org/bgfl/custom/resources_ftp/client_ftp/teacher/ict/depict_project/)

Greaves, T. (2000). One-to-one computing tools for life. T.H.E. Journal, 27(10), $54-56$.

Hawkins, J. (1997). The National Design Experiments Consortium: Final report. New York, NY: Center for Children and Technology, Educational Development Center.

Hoppe, U., Milrad, M., \& Kinshuk (2002). In M. Milrad, U. Hoppe \& Kinshuk (Eds.) Preface, In Proceedings of international workshop in wireless and mobile technologies in education (WMTE2002) Växjö University, Sweden.

Howard, R. (2005). Four decades of modern computing: A retrospective for the future. Part 2 of a two-part series. Inner Circle newsletter, Sun Microsystems, Santa Clara, USA.

Howe, N., \& Strauss, W. (2000). Millennials rising: The next great generation. New York: Vintage.

Hsi, S. (2003). A study of user experiences mediated by nomadic web content in a museum. Journal of Computer Assisted Learning, 19(3), 308-319. 
Huang, C., Liang, J., \& Wang, H. (2001). EduClick: A computer-supported formative evaluation system with wireless devices in ordinary classroom. Best paper award. In C. Lee, S. Lajoie, R. Mizoguchi, Y. Yoo \& B. Boulay (Eds.), in Proceedings of the ninth international conference on computers in education (pp. 1462-1469). Seoul, Korea.

International Telecommunication Union (2004). (http://www.itu.int/home/index.html)

Joyner, A. (2002, September). A foothold for handhelds. American School Board Journal: Special Report. Retrieved October 20, 2005. (http://www.asbj.com/specialreports/ 0903SpecialReports/S3.html)

Kasesniemi, E., \& Rautiainen, P. (2002). Mobile culture of children and teenagers in Finland. In J. E. Katz \& M. A. Aakhus (Eds.), Perceptual contact: Mobile communication, Private talk, Public Performance. New York, NY: Cambridge University Press.

Kay, A. (1971). (http://www.smalltalk.org/alankay.html)

Krajcik, J. (2005). Keynote: Using learning technologies to support students in developing integrated understanding, In International conference on computers in education, Nanyang Technology University, Singapore.

Klopfer, E., Squire, K., \& Jenkins, H. (2002, August). Environmental detectives PDAs as a window into a virtual simulated world. In Proceedings of international workshop in wireless and mobile technologies in education (WMTE2002) (pp. 95-98). August 29-30, 2002, Växjö University, Sweden.

Koedinger, K., Suthers, D., \& Forbus, K. (1999). Component-based construction of a science learning space. International Journal of Artificial Intelligence in Education, 10, 292-313. (http://cbl.leeds.ac.uk/ijaied/home.html)

Landauer, T. (1988). Education in a world of omnipotent and omniscient technology. In R. S. Nickerson \& P. P. Zodhiates (Eds.), Technology in education: Looking toward 2020 (pp. 11-24). Hillsdale, NJ: Erlbaum.

Liang, J., Liu, T., Wang, H., Chang, B., Deng, Y., Yang, J., Chou, C., Ko, W., Yang, S., \& Chan, T. (2005). A few design perspectives on one-on-one digital classroom environment. Journal of Computer Assisted Learning, 21(3), 181-189.

MIT (2005). Annan to present prototype $\$ 100$ laptop at World Summit on Information Society. MIT Tech Talk. 50(9), 4.

Mokros, J. R., \& Tinker, R. F. (1987). The impact of microcomputer-based labs on children's ability to interpret graphs. Journal of Research in Science Teaching, 24(5), 369-383.

Moore, G. (1965, April). Cramming more components onto integrated circuits, Electronics, $38(8), 114-117$.

Moore, G. A. (1991) Crossing the chasm: Marketing and selling high-tech products to mainstream customers. New York: HarperCollins Publishers.

National Center for Education Statistics. (2001). The nation's report card: Mathematics 2000. (No. NCES 2001-571). Washington DC: U.S. Department of Education.

Nielson, D. (2005). A heritage of innovation: SRI's First Half Century. Menlo Park, CA: SRI International.

Oblinger, D. (2003, July/August) Understanding the new students: Boomers, genxers, millennials, EDUCAUSE Review, 38(4), 37-47.

Owston, R. D. (2003). School context, sustainability, and transferability of innovation. In R. B. Kozma (Ed.), Technology, innovation and educational change: A global perspective, a report of the second information technology in education study, module 2. Eugene, Oregon: International Society for Technology in Education $<$ http://www.iste.org/>, International Association for the Evaluation of Educational Achievement. 
Papert, S. (1980). Mindstorms: Children, computers, and powerful ideas. New York: Basic Books.

Pea, R. D. (1993). Practices of distributed intelligence and designs for education. In G. Salomon (Ed.), Distributed cognitions (pp. 47-87). New York: Cambridge University Press.

Pea, R., Wulf, W., Elliot, S. W., \& Darling, M. (Eds.) (2003, August) Planning for two transformations in education and learning technology. Committee on Improving Learning with Information Technology. Washington, DC: National Academy Press.

Perez, C. (2002). Technological revolution and financial capital — The dynamic bubbles and golden ages. Edward Elgar Publishing Limited, UK.

Peterson, S. (2005). Wi-Fi for the masses. Government Technology, December 8. (http:// www.govtech.net/magazine/story.php?id=97512)

Pinkwart, N., Hoppe, U., Milrad, M. \& Perez, J. (2003). Educational scenarios for cooperative use of personal digital assistants. Journal of Computer Assisted Learning, 19(3), 383-391.

Rheingold, H. (2002). Smart mobs: The next social revolution. Cambridge, MA: Basic Books.

Rogers, E. M. (1995). Diffusion of innovation, Fourth Edition. New York: The Free Press.

Roschelle, J. (2003). Keynote paper: Unlocking the learning value of wireless mobile devices, Journal of Computer Assisted Learning 19(3), 260-272.

Roschelle, J., \& Pea, R. (2002). A walk on the WILD side: How wireless handhelds may change computer-supported collaborative learning. International Journal of Cognition and Technology, 1(1), 145-168.

Roschelle, J., Penuel, W. R., \& Abrahamson, L. A. (2004). The networked classroom. Educational Leadership, 61(5), 50-54.

Roschelle, J., DiGiano, C., Koutlis, M., Repenning, A., Phillips, J., Jackiw, N., \& Suthers, D. (1999). Developing educational software components. Computer, 32(9), 50-58. Piscataway, NJ: IEEE Computer Society.

Roschelle, J., \& Jackiw, N. (2000). Technology design as educational research: Interweaving imagination, inquiry and impact. In A. Kelly \& R. Lesh (Eds.), Research Design in Mathematics $\mathcal{E}$ Science Education (pp. 777-797). Mahwah, NJ: Lawrence Erlbaum Associates.

Roschelle, J., Patton, C., Chan, T. W., Brecht, J., \& Bienkowski, M., With G1:1 Members (2005). G1:1 scenarios: Envisioning the context for WMTE in 2015. In H. Ogata, M. Sharples, Kinshuk, \& Y. Yano (Eds.), in Proceedings of the third IEEE international workshop on wireless and mobile technologies in education (pp. 112-119). Tokushima University, Tokushima City, Japan, IEEE Computer Society.

Scardamalia, M. (2002). Collective cognitive responsibility for the advancement of knowledge. In B. Smith (Ed.), Liberal education in a knowledge society (pp. 67-98). Chicago: Open Court.

Scardamalia, M., \& Bereiter, C. (2003). Knowledge building. In Encyclopedia of Education. (2nd ed., pp. 1370-1373). New York: Macmillan Reference, USA.

Sharples, M. (2003). Imagining a future where buildings or public spaces are "learning enabled", ElearningEuropa.Info website, 20.1.2003. (http://www.elearningeuropa. info/index.php?page $=$ doc\&doc_id $=593 \&$ doclng $=6 \& \mathrm{~m})$

Shapshak, D. (2002). Unwiring Africa. DigAfrica 2001 (On-line), Digital Digest. (http://groups.yahoo.com/group/DigAfrica)

Staudt, C. (2002). Understanding algebra through handhelds: Feedback beamed instantly helps a teacher identify students' misconceptions and correct them during a graphing lesson. Learning and Leading with Technology, 30(2), 36-39. 
Steinkuehler, C. (2004). Learning in massively multi-player online games. In Proceedings of the sixth international conference on learning sciences (pp. 521-528). Mahwah, NJ: Lawrence Erlbaum, 2004.

Stroup, W. M., Kaput, J., Ares, N., Wilensky, U., Hegedus, S. J., Roschelle, J., et al. (2002). The nature and future of classroom connectivity: The dialectics of mathematics in the social space. Paper presented at the Psychology and Mathematics Education North America conference, Athens, GA.

Tapscott, D. (1998). Growing up digital: The rise of the net generation. New York: McGraw-Hill.

Tatar, D., Roschelle, J., Vahey, P., \& Penuel, W. R. (2003). Handhelds go to school: Lessons learned. IEEE Computer, 36(9), 30-37.

Tinker, R., \& Krajcik, J. (Eds.) (2001). Portable technologies: Science learning in context. New York: Kluwer Academic/Plenum Publishers.

Tinker, R., \& Vahey, P. (2002). CILT 2000: Ubiquitous computing, spanning the digital divide. Journal of Science Education and Technology, 11(3), 301-304.

Vahey, P., \& Crawford, V. (2002). Palm education pioneers program: Final evaluation report. Menlo Park, CA: SRI International.

Wachira, N. (2003). Wireless in Kenya takes a village. Wired. Cited in TAD Consortium February 2003 Information Update No. 2, Telematics for African.

Weiser, M. (1991). The computer for the twenty-first century, Scientific American, September issue (pp. 94-104).

Wilensky, U., \& Stroup, W. (2000). Networked gridlock: Students enacting complex dynamic phenomena with the hubnet architecture. In B. Fishman \& S. O'ConnorDivelbiss (Eds.), Fourth international conference of the learning Sciences (pp. 282289). Mahwah, NJ: Erlbaum.

Zurita, G., \& Nussbaum, M. (2004). Computer supported collaborative learning using wirelessly interconnected handheld computers. Computers \& Education, 42, 289-314. 